\title{
Leakage Performance of the GM + CCL Liner System for the MSW Landfill
}

\author{
Fan Jingjing \\ Changsha Environmental Protection Vocational College, Changsha 410004, China \\ Correspondence should be addressed to Fan Jingjing; fjj-07@163.com
}

Received 31 August 2013; Accepted 20 January 2014; Published 25 February 2014

Academic Editors: N. Gerolymos and E. Yasar

Copyright (C) 2014 Fan Jingjing. This is an open access article distributed under the Creative Commons Attribution License, which permits unrestricted use, distribution, and reproduction in any medium, provided the original work is properly cited.

The contaminants in the landfill leachate press pose a grave threat to environment of the soil and the groundwater beneath the landfill. Despite there being strict requirements in relevant provisions of both domestic and foreign countries for the design of the bottom liner system. Pollution of the soil and the groundwater still took place in a number of landfills because of the leakage. To investigate the leakage rate of the liner systems, the minimum design requirements of the liner systems are summarized according to the provisions of four countries, including China, USA, Germany, and Japan. Comparative analyses using one-dimensional transport model are conducted to study the leakage performance of these liner systems composed of geomembrance (GM) and compacted clay layer (CCL) meeting the relevant minimum design requirements. Then parametric analyses are conducted to study the effects of the hydraulic head, the thickness of GM, the hydraulic conductivity of CCL, and so forth on the leakage performance of the liner system. It is concluded that the liner system designed according to the minimum design requirements of Germany provide the best antileakage performance, while that of Japan performs the lowest. The key parameters affecting the failure time of the liner system are summarized. Finally, some suggestions for the design of the liner systems are made according to the analyses.

\section{Introduction}

With the rapid urbanization in the developing countries $[1-3]$, the increased municipal waste resulted in serious problems of the pollution [4-7]. To eliminate the adverse effects of the municipal waste to the environment, we make use of composting, incineration, and landfill to dispose the waste [8-10]. Within these approaches, the landfill is the most widely used one because it has the advantage of simplified technique, large capacity, and cost saving [11-13]. However, the leachate produced by the municipal wastes in the landfill pressed serious threat of pollution to the soil and the groundwater beneath the landfill because of the high concentration of toxic pollutants in the leachate [14-17].

To prevent the pollution of the soil and the groundwater from the leachate, we employ the liner system to block the leachate from the surroundings. The most widely used liner system is composed of a high-density polyethylene (HDPE) geomembrance (GM) over a compact clay layer (CCL) [18-23]. A number of countries, including China [24], US [25], Germany [26], and Japan [27], have released technique specifications on the liner system based on their independent experimental and analysis research. Rowe and Booker [28] conducted comparative research on three kinds of the liner system, including GM + CCL, GM + CCL + attenuation layer $(\mathrm{AL})$, and the double lined system. Rowe concluded that the standard barrier designs eventually gave rise to unacceptable impacts due to the clogging effects of the leachate collection system. Xie et al. [29] studied four types of landfill liner systems which were proposed in the Chinese specification. The conclusion was that the doublelayered GM + CCL liner system was the best barrier for the contaminant. Turan et al. $[30,31]$ conducted an intensive study on the performance of the different liner materials with bentonite on the removal efficiency of $\mathrm{Cu}(\mathrm{II})$ and $\mathrm{Zn}$ (II) from the leachate. Some design recommendations were made to improve the removal efficiencies of the liner system.

Previous studies mainly paid their attention to the leakage rate of the liner systems with different types of structures. For the GM + CCL liner system, which is the most widely used liner system, the minimum requirements are different from one specification to another. The performance 


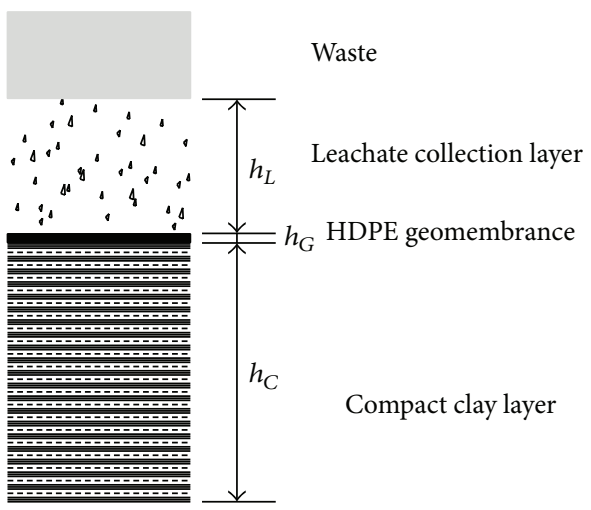

FIGURE 1: Schematics of the bottom liner system for MSW.

of the GM + CCL liner system satisfying the minimum requirements of different specifications is rarely studied. To investigate the barrier performance of the GM + CCL liner systems that meet the minimum design requirements of different specifications, we conduct a comparative study on four kinds of GM + CCL liner systems proposed in the specification of China, USA, Germany, and Japan in terms of leakage rate, mass concentration, and contaminant critical time. Then parametric analyses are conducted to study the influence of water head, thickness of GM, thickness of CCL, and so forth on the leakage performance of the liner system. Some propositions for the corresponding design provisions are proposed according to the parametric analyses.

\section{Minimum Design Requirements for the Liner System}

The schematics of the GM + CCL bottom liner system for MSW are shown in Figure 1. The function of the leachate collection layer is to collect and discharge the leachate produced by the waste. $h_{L}$ is the hydraulic head of the leachate collection layer. The high-density polyethylene (HDPE) geomembrance (GM) and the compact clay layer (CCL) are placed behind the leachate collection layer to prevent the contaminant from invading the subsoil and groundwater. $h_{G}$ and $h_{C}$ are the thickness of the HDPEGM and CCL, respectively.

The types of GM + CCL liner systems examined are as follows.

(a) Chinese specification-CJJ113-2007 Technical code for liner system of municipal solid waste landfill [24] proposed four types of liner systems, including GM + CCL, GM + geosynthetic clay liner (GCL), a single CCL, and a single GM. The GM + CCL liner system is composed of a CCL with a thickness of $0.75 \mathrm{~m}$ covered by the HDPE GM with a thickness of $1.5 \mathrm{~mm}$. The coefficient of hydraulic conductivity of the CCL should be less than $1 \times 10^{-9} \mathrm{~m} / \mathrm{s}$.

(b) US subtitle D minimum design [25] consists of a $1.5 \mathrm{~mm}$ thick HDPEGM over a $0.6 \mathrm{~m}$ thick CCL with a hydraulic conductivity of $1 \times 10^{-9} \mathrm{~m} / \mathrm{s}$.
TABLE 1: Minimum requirements for the liner system.

\begin{tabular}{lcccc}
\hline Item & China & USA & Germany & Japan \\
\hline$h_{L}(\mathrm{~m})$ & 0.3 & 0.3 & 0.3 & 0.5 \\
$h_{G}(\mathrm{~mm})$ & 1.5 & 1.5 & 2 & 1 \\
$h_{C}(\mathrm{~m})$ & 0.75 & 0.6 & 0.75 & 0.5 \\
$k_{C}\left(\mathrm{~m}^{2} / \mathrm{s}\right)$ & $1 \times 10^{-9}$ & $1 \times 10^{-9}$ & $1 \times 10^{-10}$ & $1 \times 10^{-8}$ \\
\hline
\end{tabular}

(c) German minimum design requirements for the liner system are composed of a $2.5 \mathrm{~mm}$ thick HDPEGM over a $0.75 \mathrm{~m}$ thick CCL with a hydraulic conductivity of $5 \times 10^{-10} \mathrm{~m} / \mathrm{s}$ [26].

(d) The Japanese guideline [27] specifies minimum design requirements for the liner system consisting of a $1 \mathrm{~mm}$ thick HDPEGM and a $0.5 \mathrm{~m}$ thick CCL with a hydraulic conductivity of $1 \times 10^{-8} \mathrm{~m} / \mathrm{s}$.

The minimum requirements for the liner system are summarized in Table $1 . k_{c}$ is the maximum hydraulic conductivity of the CCL. The meaning of the other items is shown in Figure 1.

\section{One-Dimensional Finite Layer Model}

3.1. Theory. The main mechanisms of the contaminant transporting through the liner system are advection and diffusion (including mechanical dispersion). One-dimensional (1D) contaminant transport analysis is performed to study the performance of the liner system. The assumptions are as follows $[32,33]$.

(a) The Source of the Contaminant Is on the Top of the Liner System. The flow in each layer during each time interval is steady state. The transient flow conditions are not considered. This assumption is checked by Rowe and Nadarajah [34]. They concluded that the neglect of the transient flow condition has little influence on the engineering practice.

(b) The Properties of Each Layer Are Uniform. These properties include the diffusion coefficient, porosity, and advective velocity. Different layers may have different properties and these properties may change at different times.

(c) The Sorption Is First Order. Based on the assumption above, the advective-diffusive-dispersive transport of the contaminant through the liner system is governed by the following:

$$
R_{d} \frac{\partial C}{\partial t}=D \frac{\partial^{2} C}{\partial z^{2}}-v \frac{\partial C}{\partial z}-\lambda C
$$

where $C$ is the concentration of the contaminant, $D$ is the coefficient of the hydrodynamic dispersion in the layer, $v$ is the Darcy velocity, and $\lambda$ is the first order sink term for modeling the contaminant removed per unit volumn:

$$
\lambda=\frac{\ln 2}{T_{1 / 2}},
$$


TABLE 2: Hydraulic conductivity, porosity, and dry density in CCL.

\begin{tabular}{lccc}
\hline \multirow{2}{*}{ Property } & \multicolumn{3}{c}{ Coefficient of conductivity $k_{\mathrm{C}}\left(\mathrm{m}^{2} / \mathrm{s}\right)$} \\
& $1 \times 10^{-8}$ & $1 \times 10^{-9}$ & $1 \times 10^{-10}$ \\
\hline Porosity $n$ & 0.42 & 0.35 & 0.28 \\
Dry density $\left(\mathrm{g} / \mathrm{cm}^{3}\right)$ & 1.69 & 1.79 & 1.90 \\
\hline
\end{tabular}

where $T_{1 / 2}$ is the half-life of the contaminant, and $R_{d}$ is the decay coefficient:

$$
R_{d}=1+\frac{\rho K_{d}}{n},
$$

where $\rho$ is the dry density of the layer, $K_{d}$ is the distribution coefficient, and $n$ is the porosity of the layer.

The finite layer technique proposed by Rowe and Booker [32] is adopted to solve the governing equation. The solving steps include

(1) simplifying the partial differential equation by performing a Laplace transform and solving the simplified equation analytically;

(2) performing an inverting Laplace transform to the solution in the previous step numerically and obtaining the numerical solution of the governing equation.

3.2. Landfill Model. The landfill considered has a length of $200 \mathrm{~m}$ in the direction of the groundwater flow. Two contaminants are considered. They are $\mathrm{Cd}^{2+}$ and the dichloromethane. The two contaminants are chosen because they are common in the leachate and the data of concentration are easily available. $\mathrm{Cd}^{2+}$ represents the heavy metal in the leachate. The initial concentration for $\mathrm{Cd}^{2+}$ is $1 \mathrm{mg} / \mathrm{L}$ [29]. The dichloromethane represents the organic pollutant in the leachate. The initial concentration of the dichloromethane is $5 \mathrm{mg} / \mathrm{L}$ [35]. According the US drinking water standards, the maximum contaminant level (MCL) for $\mathrm{Cd}^{2+}$ and the dichloromethane are $0.01 \mathrm{mg} / \mathrm{L}$ and $0.005 \mathrm{mg} / \mathrm{L}$, respectively. The relative critical concentration for $\mathrm{Cd}^{2+}$ and the dichloromethane are 0.01 and 0.001 , respectively. The hydraulic conductivity, porosity, and dry density are related to each other. The relationship proposed by Mesri and Braja $[36,37]$ is adopted, as listed in Table 2 . The contaminant characteristics are determined according to Rowe et al. [38], as shown in Table 3.

\section{Analysis Results and Discussion}

The concentration versus time curves is shown in Figure 2. The concentration increases with the increase of the time. For a given time, the concentration of the contaminant is the highest for the liner system of the Japanese standard, followed by that of the US standard and that of the Chinese standard. The concentration of the contaminant is the lowest for liner system of the German standard. The reason is that the thickness of the GM and the CCL are the largest and the hydraulic conductivity is the smallest in the liner system of the German standard. While the thicknesses of the GM
TABLE 3: Characteristics of the contaminant transportation.

\begin{tabular}{lcc}
\hline Item & $\mathrm{Cd}^{2+}$ & Dichloromethane \\
\hline Initial concentration $(\mathrm{mg} / \mathrm{L})$ & 1 & 5 \\
$\mathrm{MCL}(\mathrm{mg} / \mathrm{L})$ & 0.01 & 0.005 \\
$\begin{array}{l}\text { Diffusion coefficient of GM }\left(\mathrm{m}^{2} / \mathrm{s}\right) \\
\text { Diffusion coefficient of CCL }\left(\mathrm{m}^{2} / \mathrm{s}\right)\end{array}$ & $6 \times 10^{-15}$ & $2.1 \times 10^{-13}$ \\
$\begin{array}{l}\text { Adsorption coefficient of CCL } K_{d} \\
(\mathrm{~mL} / \mathrm{g})\end{array}$ & 0.36 & $5.7 \times 10^{-10}$ \\
\hline
\end{tabular}

TABLE 4: Critical times of the liners/year.

\begin{tabular}{lcc}
\hline Type & $\mathrm{Cd}^{2+}$ & Dichloromethane \\
\hline China & 79.1 & 20.7 \\
USA & 57.3 & 13.4 \\
Germany & 168.4 & 26.8 \\
Japan & 13.3 & 8.1 \\
\hline
\end{tabular}

and the CCL are the smallest and the hydraulic conductivity is the largest in the liner system of the Japanese standard, it is indicated that the minimum requirements in German standard are the most conservative, while those in Japanese standard are the most economic.

The time at which the concentration at the bottom of the liner system reaches the MCL is defined as the critical time. The critical times of the four types of the liner system are listed in Table 4. The liner system of the German standard has the longest critical time, while that of the Japanese standard has the shortest critical time. The critical time of the dichloromethane is shorter than that of $\mathrm{Cd}^{2+}$ because the diffusion coefficient of the dichloromethane is larger than that of $\mathrm{Cd}^{2+}$.

The concentration versus depth curves is shown in Figures 3 and 4 . At year 10, the concentration at the top of CCL $(z=0)$ is the largest for the Japanese liner system and is the smallest for the German liner system. The concentration at the top of CCL is very close for the US liner system and the Chinese liner system. At year 100, the distribution of the concentration at the top of CCL is similar to that at year 10 . The gradient of the concentration at year 100 is smaller than that at year 10, which indicates that the concentration along the depth tends to be uniformly distributed with the increase of time. The difference of the concentrations at the top of CCL for $\mathrm{Cd}^{2+}$ is greater than that for the dichloromethane. The reason might be that the difference of the diffusion coefficient in GM and CCL for $\mathrm{Cd}^{2+}$ is greater than that for dichloromethane.

\section{Parametric Analysis}

To investigate the performance of the GM + CCL liner system comprehensively, parametric analyses are conducted based on the Chinese liner system. The values of the parameters studied are listed in Table 5. The parameters include the hydraulic head of the leachate collection system $h_{w}$, the thickness of GM $h_{G}$, the defects of GM, the thickness of CCL $h_{C}$, and the coefficient of conductivity. Because of time and 


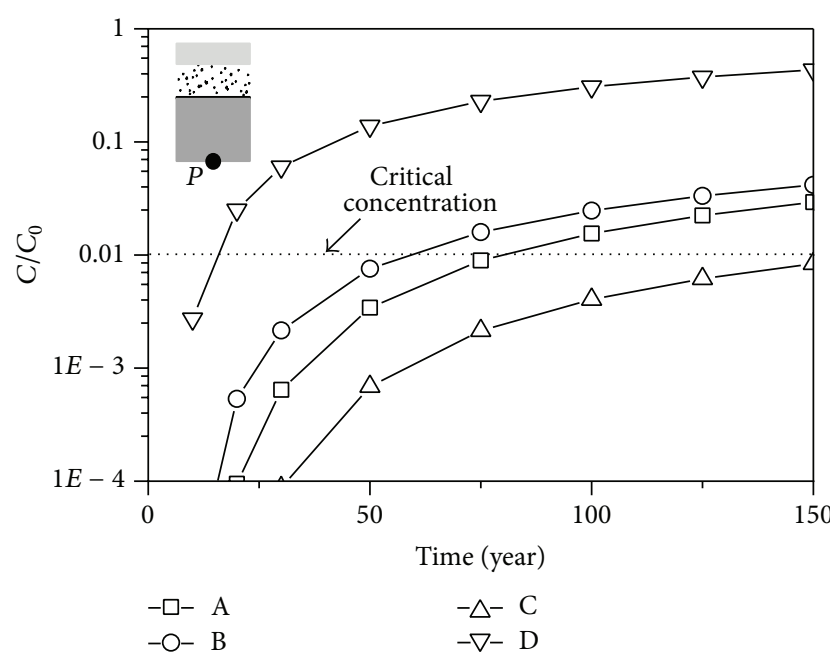

(a) $\mathrm{Cd}^{2+}$

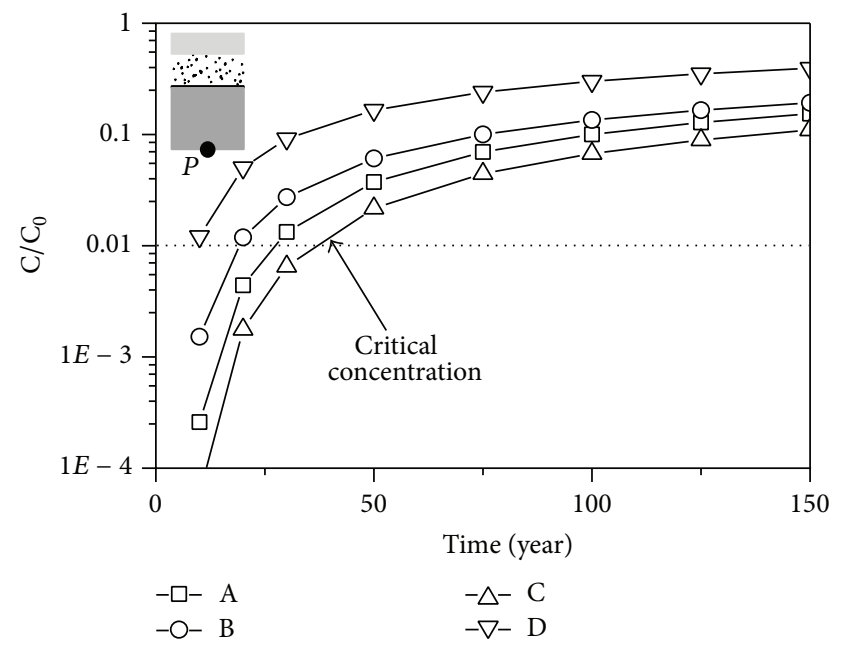

(b) Dichloromethane

FIGURE 2: The concentration-time curves of the contaminants.

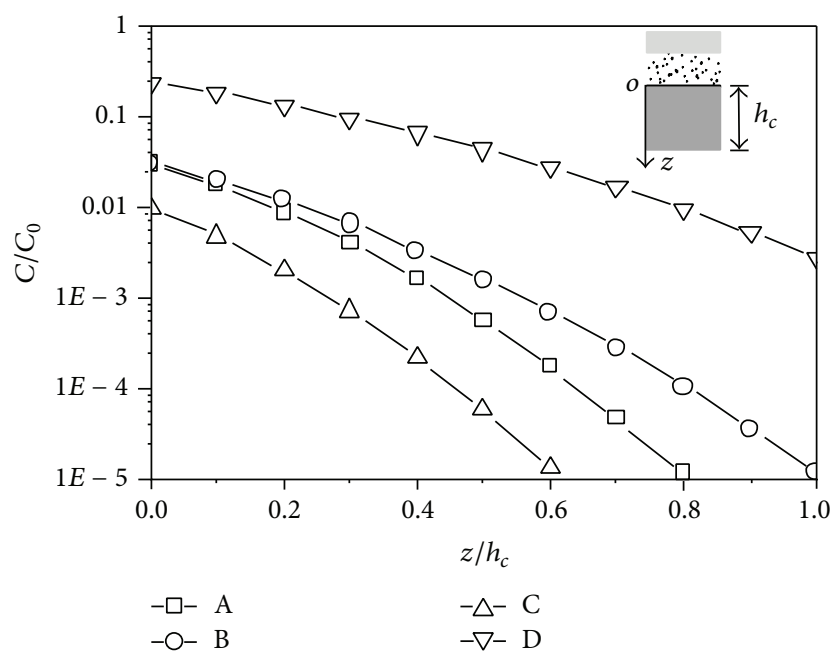

(a) Year 10

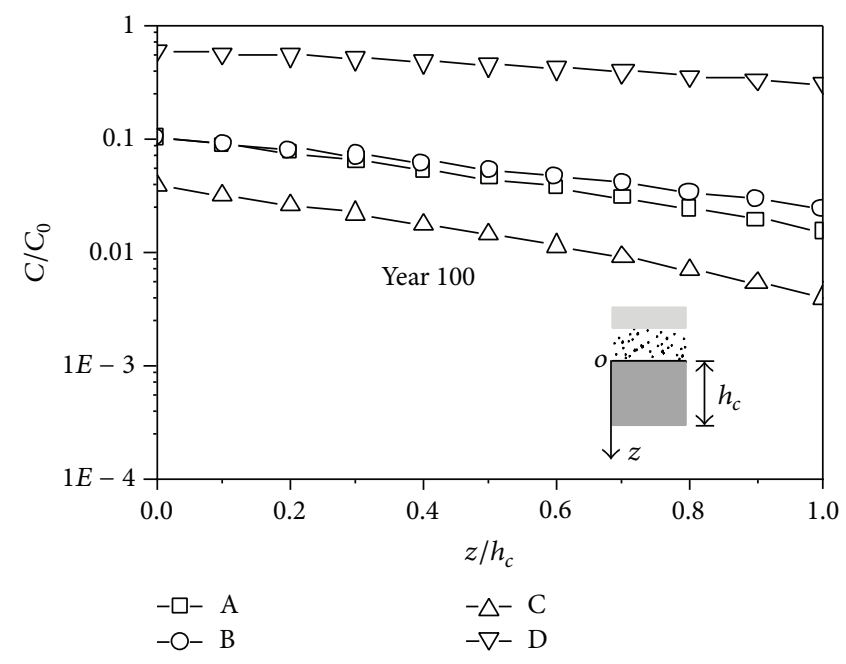

(b) Year 100

FIGURE 3: The concentration-depth curves of the $\mathrm{Cd}^{2+}$.

TABLE 5: Variables for parametric study.

\begin{tabular}{lcccc}
\hline Parameters & \multicolumn{5}{c}{ Value } \\
\hline Hydraulic head/m & 0.3 & 1.0 & 5.0 & 10.0 \\
The thickness of GM/mm & 1.0 & 1.5 & 2.0 & 2.5 \\
The defects of GM/holes/ha & 2 & 20 & 200 & - \\
The thickness of CCL/m & 0.5 & 1.0 & 2.0 & 3.0 \\
Coefficient of conductivity/ms & $1 \times 10^{-8}$ & $1 \times 10^{-9}$ & $1 \times 10^{-10}$ & - \\
\hline
\end{tabular}

space limitations, attention is paid to the migration behavior of $\mathrm{Cd}^{2+}$.

5.1. Hydraulic Head of the Leachate Collection System. The function of the leachate collection system is to limit the head acting on the liner system. In the life-cycle of the landfill, the permeability of the leachate collection system decreases with the physical, chemical, and biological corrosion. If the hydraulic head of leachate collection system exceeds the design value, the leachate collection system is not able to perform its primary function and the liner system is easier to be broken through. This condition is called clogged. Four types of the hydraulic head are considered. They are $0.3 \mathrm{~m}$, $1 \mathrm{~m}, 5.0 \mathrm{~m}$, and $10.0 \mathrm{~m}$. The concentration versus time curves is shown in Figure 5. The concentration increases with the increase of the hydraulic head. The critical times of the liner system with a hydraulic head of $0.3 \mathrm{~m}, 1 \mathrm{~m}, 5.0 \mathrm{~m}$, and $10.0 \mathrm{~m}$ are 79.1 years, 45.3 years, 21.0 years, and 11.4 years, respectively.

5.2. The Thickness of the GM. The seepage performance of the GM has been widely recognized with the development of the 


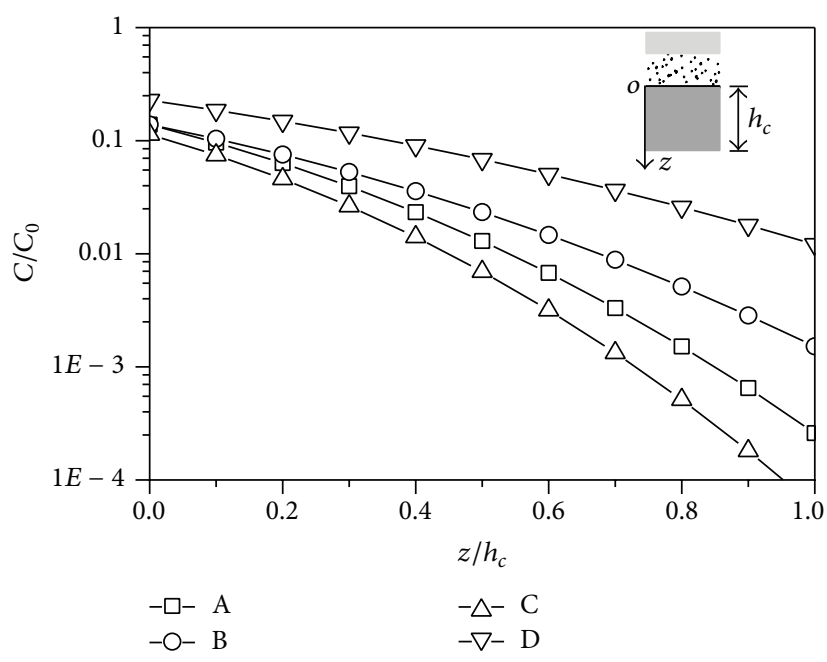

(a) Year 10

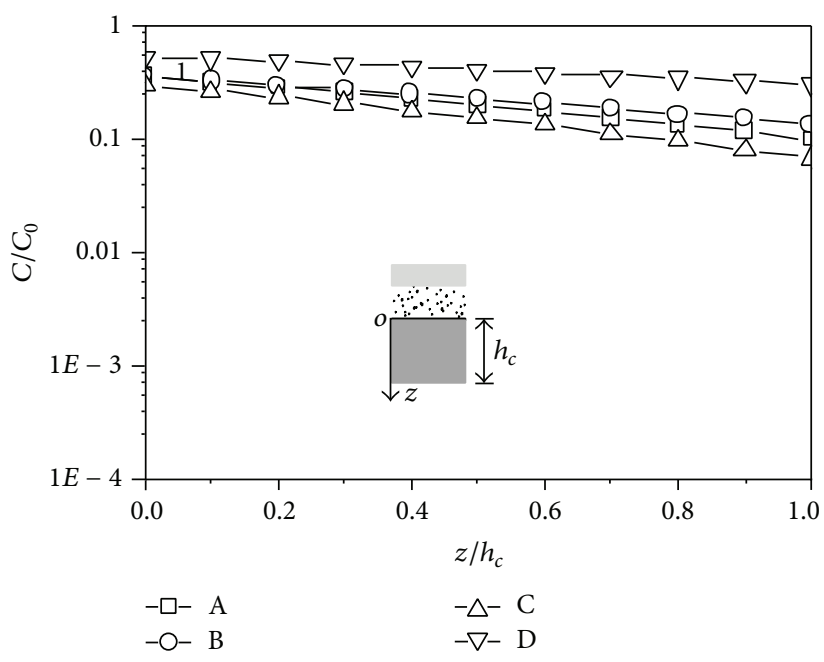

(b) Year 100

Figure 4: The concentration-depth curves of the dichloromethane.

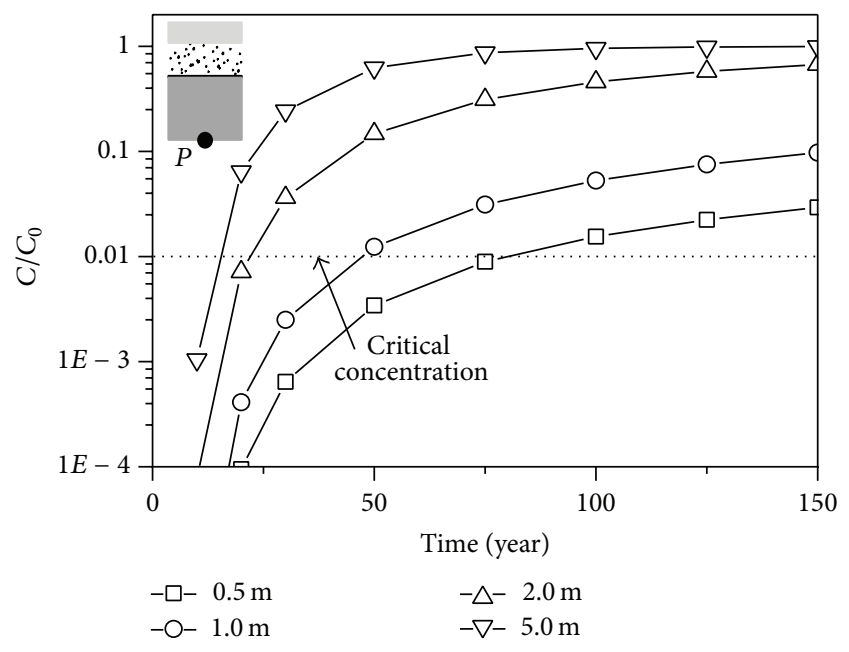

FIGURE 5: Comparison of numerical results with different water heads.

geotextile material technology. The GM has good durability and elongation properties subjected to tension. It is economic in transportation and construction. Therefore, the GM is widely used in the landfill liner system. The thickness of the GM studied includes $1 \mathrm{~mm}, 1.5 \mathrm{~mm}, 2 \mathrm{~mm}$, and $2.5 \mathrm{~mm}$. The concentration versus depth curves for different thickness is shown in Figure 6. The concentration of the contaminant at the top of CCL is insensitive to the thickness of the GM. The influence of the thickness of the GM to the seepage behavior of the liner system decreases with the increase of time. At year 100 , the concentrations of the contaminant are almost equal for different GM thicknesses.

5.3. The Defects of GM. The GM is prone to puncturing in the production and construction process, which results in defects of GM. The leakage of the contaminant through the defects is believed to be the main migration way through the GM [39]. Well, ordinarily, and badly constructed GM are assumed to have a defect number of 2 holes/ha, 20 holes/ha, and 200 holes/ha, respectively. The concentration versus depth curves for different numbers of defects is shown in Figure 7. The concentration at the top of CCL increases significantly with the increase of defects. The influence remains with the increase of the time, which confirms that the migration of the pollutants into the GM is mainly caused by the leakage through the defects, rather than by diffusion.

5.4. The Thickness of the CCL. The concentration versus depth curves for various thicknesses of CCL is shown in Figure 8. The concentration of the contaminant at the top of CCL remains with the increase of the thickness of CCL. It is indicated that the thickness of the CCL has little effect on the concentration at the top of CCL. The concentration at the bottom of CCL decreases remarkably with the increase of the thickness of CCL. The concentration at the bottom of CCL versus time curves is shown in Figure 9. The critical times increase almost three times when the thickness of the CCL increases from $0.5 \mathrm{~m}$ to $1.0 \mathrm{~m}$, which indicates that increasing the thickness of the CCL is beneficial to the seepage behavior of the liner system.

5.5. The Hydraulic Conductivity of the CCL. The minimum design requirements of hydraulic conductivity are different from one country to another. The effects of the hydraulic conductivity on the seepage behavior of the liner system are shown in Figure 10. The concentration decreased notably with the decrease of the hydraulic conductivity. The critical times of the liner system are 33 years, 79.1 years, and 146.7 years when the values of the hydraulic conductivity are $1 \times 10^{-8} \mathrm{~m} / \mathrm{s}, 1 \times 10^{-9} \mathrm{~m} / \mathrm{s}$, and $1 \times 10^{-10} \mathrm{~m} / \mathrm{s}$, respectively, which indicates that the seepage behavior of the liner system 


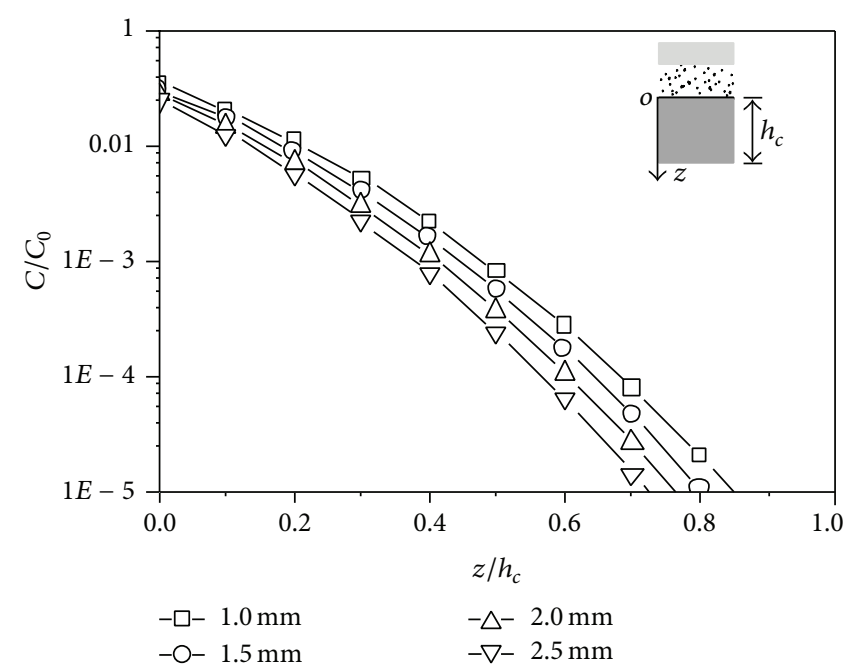

(a) Year 10

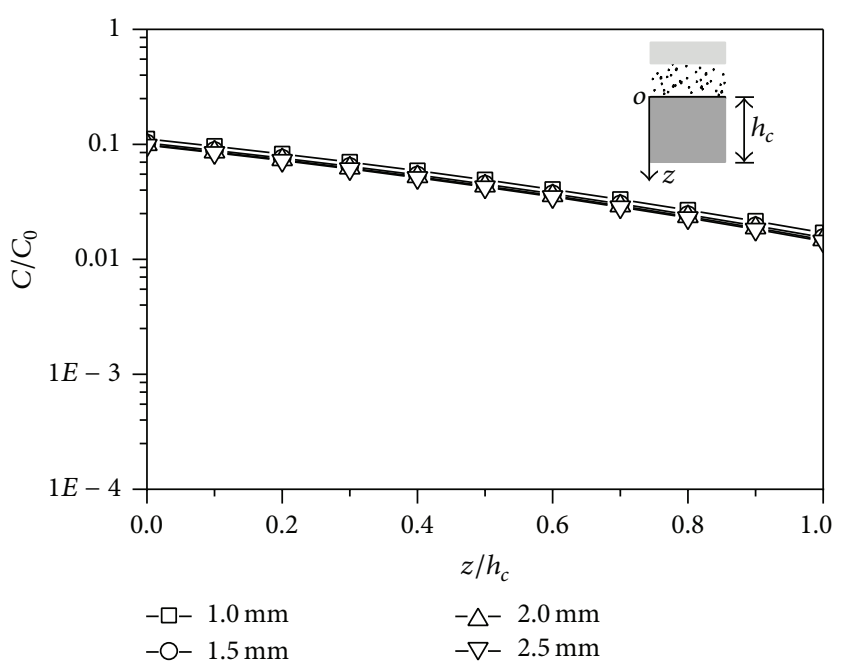

(b) Year 100

FIGURE 6: Comparison of numerical results with different GM thicknesses.

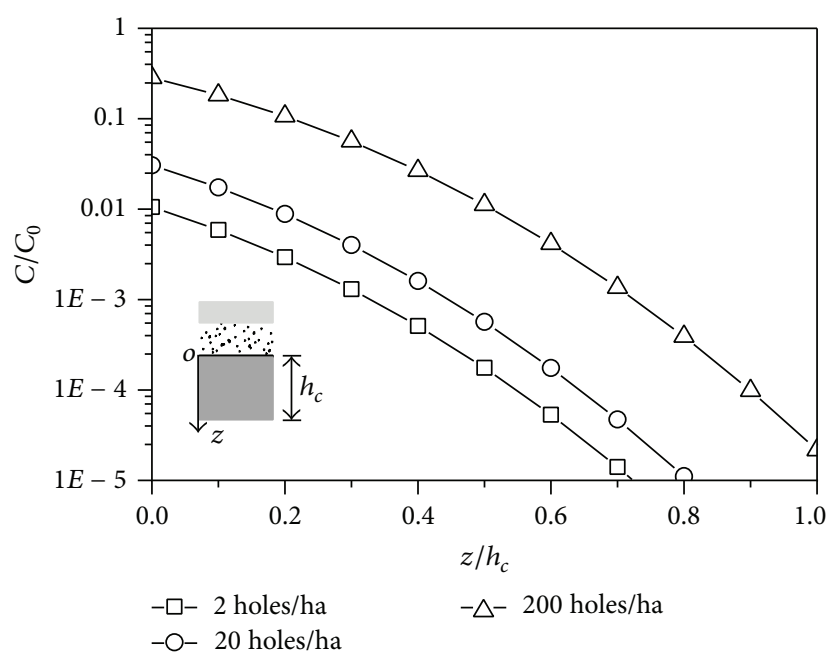

(a) Year 10

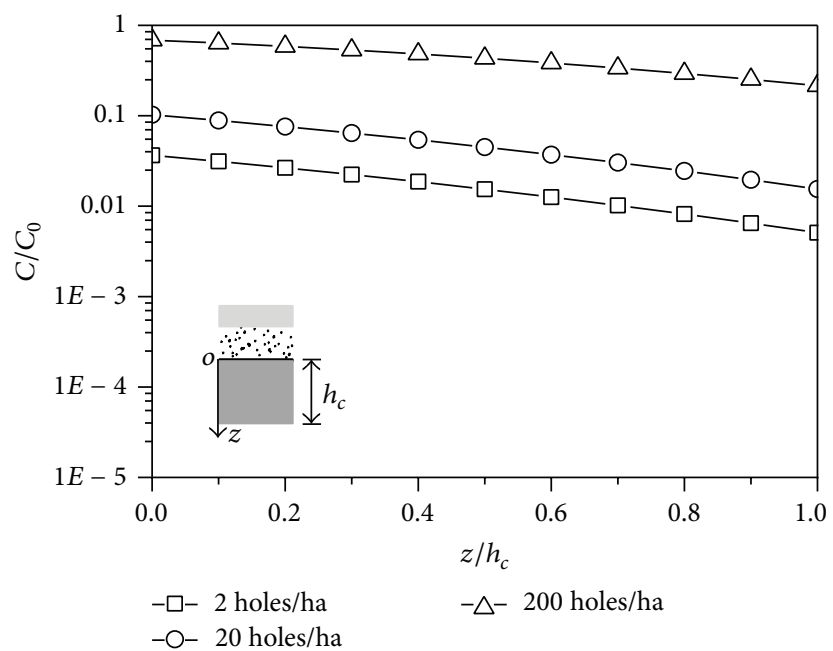

(b) Year 100

FIGURE 7: Comparison of numerical results with different GM defect holes.

improve significantly with the decrease of the hydraulic conductivity.

5.6. Leakage Characteristics of the Liner Systems. The concentration at the top of CCL, the concentration at the bottom of CCL, and the critical time are selected as the leakage characteristics of the liner systems. The leakage characteristics are listed in Table 6 . The parameters affecting the concentration at the top of CCL include the hydraulic head, defects of the GM, and the hydraulic conductivity of the CCL. The concentration at the top of CCL increases with the increase of hydraulic head, number of defects on the GM, and the hydraulic conductivity of the CCL. The influence of the hydraulic head increases with the increase of time, while that of the number of the defects and the hydraulic conductivity are insensitive with the changing of time. The main factors influencing the concentration at the bottom of CCL are the hydraulic head, the number of the defects, the thickness of the CCL, and the hydraulic conductivity. The concentration at the bottom of the CCL increases with the increase of the hydraulic head, the number of defects, and the hydraulic conductivity, while the concentration at the bottom of the CCL decreases with the increase of the thickness of the CCL. The influences of the hydraulic head and the number of defects on GM to the bottom concentration are insensitive to the increase of time. The influences of the thickness of CCL and the hydraulic conductivity to the bottom concentration increase rapidly with the increase of time. The key factors affecting the critical time are the hydraulic head, the number of defects, the thickness of CCL, and the hydraulic conductivity. The critical time decreases with the increase of 


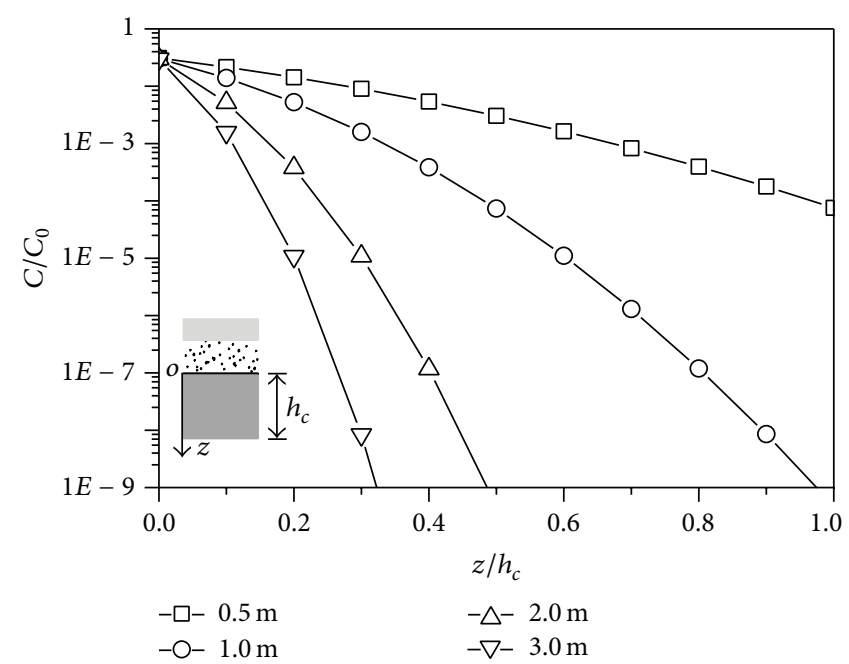

(a) Year 10

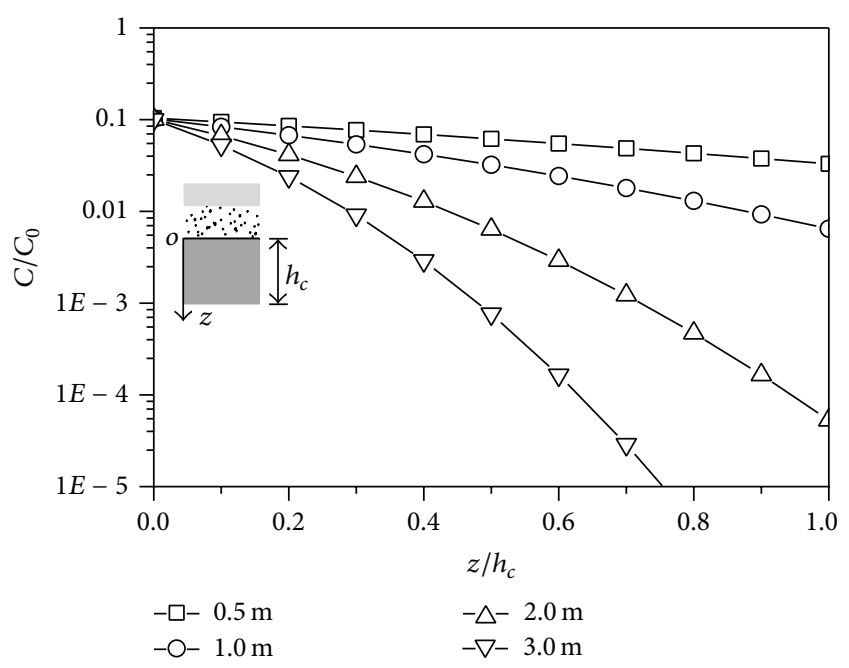

(b) Year 100

FIGURE 8: Comparison of numerical results with different CCL thicknesses.

TABLE 6: Leakage characteristics of the liner systems.

\begin{tabular}{|c|c|c|c|c|c|c|}
\hline \multirow{2}{*}{ Parameters } & \multirow{2}{*}{ Value } & \multicolumn{2}{|c|}{ Top concentration $C / C_{0}$} & \multicolumn{2}{|c|}{ Bottom concentration $C / C_{0}$} & \multirow{2}{*}{ Critical time (year) } \\
\hline & & Year 10 & Year 100 & Year 10 & Year 100 & \\
\hline \multirow{4}{*}{ Hydraulic head (m) } & 0.3 & $3.06 \times 10^{-2}$ & $4.11 \times 10^{-7}$ & $1.03 \times 10^{-1}$ & $1.55 \times 10^{-2}$ & 79.1 \\
\hline & 1.0 & $9.51 \times 10^{-2}$ & $2.52 \times 10^{-6}$ & $2.87 \times 10^{-1}$ & $5.28 \times 10^{-2}$ & 45.3 \\
\hline & 5.0 & $4.66 \times 10^{-1}$ & $7.81 \times 10^{-5}$ & $8.99 \times 10^{-1}$ & $4.59 \times 10^{-1}$ & 21.0 \\
\hline & 10.0 & $8.13 \times 10^{-1}$ & $1.05 \times 10^{-3}$ & $9.99 \times 10^{-1}$ & $9.58 \times 10^{-1}$ & 11.4 \\
\hline \multirow{4}{*}{ The thickness of GM (mm) } & 1.0 & $3.50 \times 10^{-2}$ & $1.11 \times 10^{-1}$ & $8.85 \times 10^{-7}$ & $1.70 \times 10^{-2}$ & 75.3 \\
\hline & 1.5 & $3.06 \times 10^{-2}$ & $1.03 \times 10^{-1}$ & $4.11 \times 10^{-7}$ & $1.55 \times 10^{-2}$ & 79.1 \\
\hline & 2.0 & $2.77 \times 10^{-2}$ & $9.95 \times 10^{-2}$ & $1.81 \times 10^{-7}$ & $1.48 \times 10^{-2}$ & 81.1 \\
\hline & 2.5 & $2.48 \times 10^{-2}$ & $9.81 \times 10^{-2}$ & $7.55 \times 10^{-8}$ & $1.44 \times 10^{-2}$ & 82.6 \\
\hline \multirow{3}{*}{ The defects of GM (holes/ha) } & 2 & $1.06 \times 10^{-2}$ & $3.65 \times 10^{-2}$ & $1.15 \times 10^{-7}$ & $5.09 \times 10^{-3}$ & 153.0 \\
\hline & 20 & $3.06 \times 10^{-2}$ & $1.03 \times 10^{-1}$ & $4.11 \times 10^{-7}$ & $1.55 \times 10^{-2}$ & 79.1 \\
\hline & 200 & $2.84 \times 10^{-1}$ & $6.86 \times 10^{-1}$ & $2.17 \times 10^{-5}$ & $2.15 \times 10^{-1}$ & 27.3 \\
\hline \multirow{4}{*}{ The thickness of CCL (m) } & 0.5 & $3.11 \times 10^{-2}$ & $1.04 \times 10^{-1}$ & $7.57 \times 10^{-5}$ & $3.30 \times 10^{-2}$ & 44.3 \\
\hline & 1.0 & $3.04 \times 10^{-2}$ & $1.02 \times 10^{-1}$ & $4.79 \times 10^{-10}$ & $6.47 \times 10^{-3}$ & 120.4 \\
\hline & 2.0 & $3.00 \times 10^{-2}$ & $1.01 \times 10^{-1}$ & $3.91 \times 10^{-18}$ & $5.31 \times 10^{-5}$ & 905.2 \\
\hline & 5.0 & $2.99 \times 10^{-2}$ & $1.00 \times 10^{-1}$ & $9.88 \times 10^{-26}$ & $4.37 \times 10^{-8}$ & $>1000$ \\
\hline \multirow{3}{*}{ The coefficient of conductivity $(\mathrm{m} / \mathrm{s})$} & $1 \times 10^{-8}$ & $1.48 \times 10^{-1}$ & $4.18 \times 10^{-1}$ & $1.90 \times 10^{-5}$ & $1.03 \times 10^{-1}$ & 33.0 \\
\hline & $1 \times 10^{-9}$ & $3.06 \times 10^{-2}$ & $1.03 \times 10^{-1}$ & $4.11 \times 10^{-7}$ & $1.55 \times 10^{-2}$ & 79.1 \\
\hline & $1 \times 10^{-10}$ & $1.35 \times 10^{-2}$ & $4.66 \times 10^{-2}$ & $2.25 \times 10^{-8}$ & $5.08 \times 10^{-3}$ & 146.7 \\
\hline
\end{tabular}

the hydraulic head, the number of defects on GM, and the hydraulic conductivity. The critical time increases with the increase of the thickness of the CCL. Therefore, the ways to improve the leakage behavior of the liner system include reducing the hydraulic head of the leachate collection system and the hydraulic conductivity of the CCL, controlling the quality of the construction to lessen the number of defects on the GM and increasing the thickness of the CCL.

\section{Conclusion}

The finite layer model is adopted to simulate the leakage behavior of the landfill liner system. The minimum design requirements of four countries for the liner system are compared. Parametric analyses are conducted to study the main parameter affecting the leakage behavior of the liner system. The conclusions are as follows. 


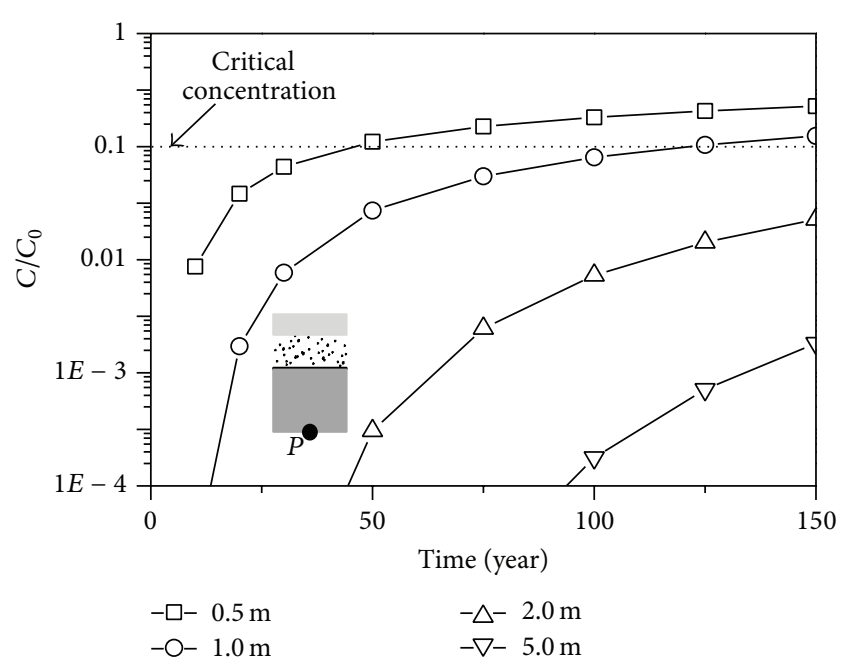

FIGURE 9: Comparison of concentration-time with different CCL thicknesses.

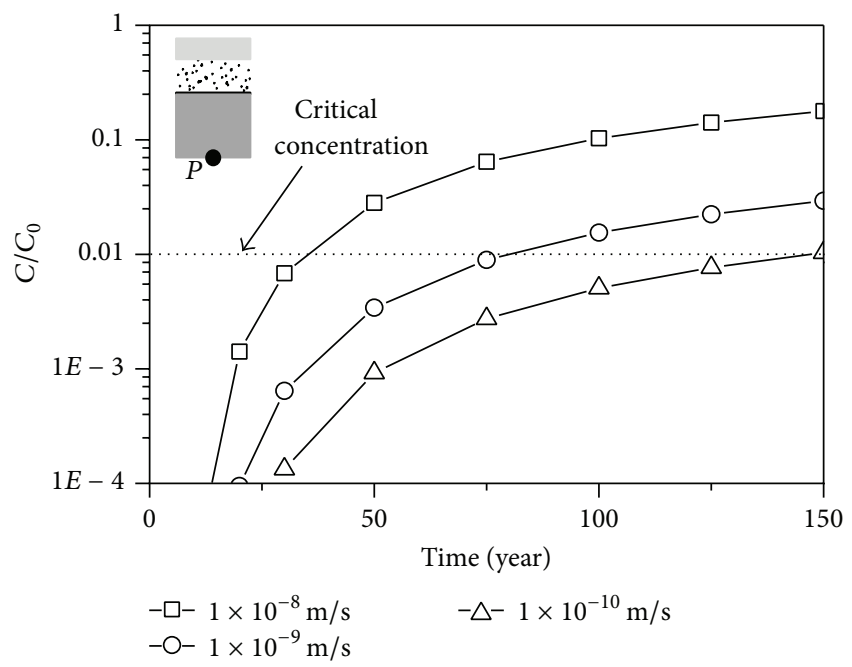

Figure 10: Comparison of numerical results with different conductivities.

(1) The minimum designed liner system according to the German specification has the best antileakage behavior, while that according to the Japanese specification has the worst antileakage performance among the minimum designed liner systems in China, US, German, and Japan. The performance of the minimum designed liner systems in China and US is similar and locates in the middle of that among the four counties.

(2) The thickness of the GM has little effects on the critical time, the concentration at the top of the CCL, and the concentration at the bottom of the CCL. The main way for the migration of the contaminant in the GM is through the defects.

(3) The concentration at the top of CCL increases with the increase of the hydraulic head, the number of defects on GM, and the hydraulic conductivity. The bottom concentration becomes larger with the increase of the hydraulic head, the number of defects on GM, and the hydraulic conductivity. The bottom concentration decreases with the increase of the thickness of the CCL.

(4) The critical time of the liner system lessens with the increase of hydraulic head, the number of defects on GM, and the hydraulic conductivity, while the critical time increases with the increase of the thickness of the CCL. The ways to control the leakage behavior of the liner system are reducing the hydraulic head, the number of defects on GM, and the hydraulic conductivity, as well as increasing the thickness of the CCL.

\section{Conflict of Interests}

The author declares that there is no conflict of interests regarding the publication of this paper.

\section{Acknowledgments}

This study was supported by the Twelfth Five Year Plan Project of Education Science Foundation of Hunan (Grant no. XJK013CZY012) and the Changsha Environmental protection vocational College Foundation (Grant no. 2013M005). These supports are gratefully acknowledged. Guidance provided by Dr. Huang was greatly appreciated.

\section{References}

[1] X. H. Xia and Y. Hu, "Determinants of electricity consumption intensity in China: analysis of cities at subprovince and prefecture levels in 2009," The Scientific World Journal, vol. 2012, Article ID 496341, 11 pages, 2012.

[2] P. K. Mallupattu and J. R. S. Reddy, "Analysis of land use/land cover changes using remote sensing data and GIS at an Urban Area, Tirupati, India," The Scientific World Journal, vol. 2013, Article ID 268623, 6 pages, 2013.

[3] Y. N. Hu, X. P. Liu, J. M. Bai, K. M. Shih, E. Y. Zeng, and H. F. Cheng, "Assessing heavy metal pollution in the surface soils of a region that had undergone three decades of intense industrialization and urbanization," Environmental Science and Pollution Research, vol. 20, no. 9, pp. 6150-6159, 2013.

[4] N. Tzortzakis, S. Gouma, C. Paterakis, and T. Manios, "Deployment of municipal solid wastes as a substitute growing medium component in marigold and basil seedlings production," The Scientific World Journal, vol. 2012, Article ID 285874, 6 pages, 2012.

[5] H. X. Zhang and T. Shimaoka, "Formation of humic substances in weathered MSWI bottom ash," The Scientific World Journal, vol. 2013, Article ID 384806, 5 pages, 2013.

[6] N. Tzortzakis, S. Gouma, E. Dagianta et al., "Use of fertigation and municipal solid waste compost for greenhouse pepper cultivation," The Scientific World Journal, vol. 2012, Article ID 973193, 8 pages, 2012.

[7] H. X. Zhao, X. J. Duan, B. Stewart, B. S. You, and X. W. Jiang, "Spatial correlations between urbanization and river water pollution in the heavily polluted area of Taihu Lake Basin, 
China," Journal of Geographical Sciences, vol. 23, no. 4, pp. 735752, 2013.

[8] Y. Wang, C. Lin, J. Li, N. Duan, X. Li, and Y. Y. Fu, "Emergy analysis of biogas systems based on different raw materials," The Scientific World Journal, vol. 2013, Article ID 415812, 9 pages, 2013.

[9] Y. Li, Leachate Processing Technology and Engineering Practice, China Environmental Science Press, Beijing, China, 2008.

[10] T. Hu, G. Zeng, and X. Yuan, "Decision-making mode of integrated disposal scheme for regional municipal solid waste," Journal of Hunan University Natural Sciences, vol. 29, no. 2, pp. 79-87, 2002.

[11] X. B. Feng, S. L. Tang, Z. G. Li, S. F. Wang, and L. Liang, "Landfill is an important atmospheric mercury emission source," Chinese Science Bulletin, vol. 49, no. 19, pp. 2068-2072, 2004.

[12] Y. Chen, D. Gao, B. Zhu, and R. Chen, "Seismic stability and permanent displacement of landfill along liners," Science in China E, vol. 51, no. 4, pp. 407-423, 2008.

[13] S. Devaramani and P. Malingappa, "Micelle mediated trace level sulfide quantification through cloud point extraction," The Scientific World Journal, vol. 2012, Article ID 152016, 8 pages, 2012.

[14] L. Changli, Z. Feng-E, Z. Yun et al., "Experimental and numerical study of pollution process in an aquifer in relation to a garbage dump field," Environmental Geology, vol. 48, no. 8, pp. 1107-1115, 2005.

[15] Y. J. Du, S. L. Shen, S. Y. Liu, and S. Hayashi, "Contaminant mitigating performance of Chinese standard municipal solid waste landfill liner systems," Geotextiles and Geomembranes, vol. 27, no. 3, pp. 232-239, 2009.

[16] J. Kalka, "Landfill leachate toxicity removal in combined treatment with municipal wastewater," The Scientific World Journal, vol. 2012, Article ID 202897, 7 pages, 2012.

[17] K. Widziewicz, J. Kalka, M. Skonieczna, and P. Madej, “The comet assay for the evaluation of genotoxic potential of landfill leachate," The Scientific World Journal, vol. 2012, Article ID 435239, 8 pages, 2012.

[18] J. K. Mitchell, "Geotechnical surprises—or are they?" Journal of Geotechnical and Geoenvironmental Engineering, vol. 135, no. 8, pp. 998-1010, 2009.

[19] S. Dickinson and R. W. I. Brachman, "Assessment of alternative protection layers for a geomembrane-geosynthetic clay liner (GM-GCL) composite liner," Canadian Geotechnical Journal, vol. 45, no. 11, pp. 1594-1610, 2008.

[20] Y. Chen, H. Xie, H. Ke, and R. Chen, "An analytical solution for one-dimensional contaminant diffusion through multi-layered system and its applications," Environmental Geology, vol. 58, no. 5, pp. 1083-1094, 2009.

[21] G. J. Foose, "Transit-time design for diffusion through composite liners," Journal of Geotechnical and Geoenvironmental Engineering, vol. 128, no. 7, pp. 590-601, 2002.

[22] R. K. Rowe, T. Mukunoki, R. J. Bathurst, S. Rimal, P. Hurst, and S. Hansen, "Performance of a geocomposite liner for containing Jet A-1 spill in an extreme environment," Geotextiles and Geomembranes, vol. 25, no. 2, pp. 68-77, 2007.

[23] R. K. Rowe, S. Rimal, and H. Sangam, "Ageing of HDPE geomembrane exposed to air, water and leachate at different temperatures," Geotextiles and Geomembranes, vol. 27, no. 2, pp. 137-151, 2009.

[24] Technical Code for Liner System of Municipal Solid Waste Landfill, CJJ113-2007, China Architecture and Building Press, Beijing, China, 2007.
[25] Criteria for Municipal Solid Waste Landfills, vol. 40 of CFR Ch 258.5, Environmental Protection Agency, New York, NY, USA, 2011.

[26] "Manassero: controlled landfill design," in Environmental Geotechnics, pp. 77-112, Technical Committee TC 5 on Environmental Geotechnics, Bochum, Germany, 1997.

[27] Japanese Ministry of Health and Welfare, Guidelines for the Performance of MSW Landfills, S9005-01, Japanese Ministry of Health and Welfare, Tokyo, Japan, 2001.

[28] R. K. Rowe and J. R. Booker, "Recent advances in modelling contaminant impact due to clogging," in Proceedings of the 9th International Conference of the Association for Computer Methods and Advances in Geomechanics, vol. 1, pp. 43-56, Wuhan, China, 1997.

[29] H. Xie, L. Zhan, Y. Chen, and Z. Lou, "Comparison of the performance of four types of liner systems in China," China Civil Engineering Journal, vol. 44, no. 7, pp. 133-141, 2011.

[30] N. G. Turan, E. B. Gumusel, and O. Ozgonenel, "Prediction of heavy metal removal by different liner materials from landfill leachate: modeling of experimental results using artificial intelligence technique," The Scientific World Journal, vol. 2013, Article ID 240158, 5 pages, 2013.

[31] N. G. Turan and O. Ozgonenel, "The design and implementation of adsorptive removal of $\mathrm{Cu}$ (II) from leachate using ANFIS," The Scientific World Journal, vol. 2013, Article ID 590267, 9 pages, 2013.

[32] R. K. Rowe and J. R. Booker, "A finite layer technique for modelling complex landfill history," Canadian Geotechnical Journal, vol. 32, no. 4, pp. 660-676, 1995.

[33] H. J. Xie, Z. H. Lou, Y. M. Chen, A. M. Jin, T. L. Zhan, and X. W. Tang, "An analytical solution to organic contaminant diffusion through composite liners considering the effect of degradation," Geotextiles and Geomembranes, vol. 36, pp. 10-18, 2013.

[34] R. K. Rowe and P. Nadarajah, "An analytical method for predicting the velocity field beneath landfills," Canadian Geotechnical Journal, vol. 34, no. 2, pp. 264-282, 1997.

[35] Z. Lou, Leachate Treatment and Disposal Technology and Engineering Practice, Chemical Industrial Press, Beijing, China, 2007.

[36] G. Mesri and R. E. Olson, "Mechanisms controlling the permeability of clays," Clays and Clay Minerals, vol. 19, no. 3, pp. 151$158,1971$.

[37] M. D. Braja, Advanced Soil Mechanics, Taylor \& Francis, New York, NY, USA, 2008.

[38] R. Rowe, R. Quigley, and R. Brachman, Barrier Systems for Waste Disposal Facilities, Spon Press, New York, NY, USA, 2004.

[39] J. P. Giroud, "Equations for calculating the rate of liquid migration through composite liners due to geomembrane defects," Geosynthetics International, vol. 4, no. 3-4, pp. 335-348, 1997. 

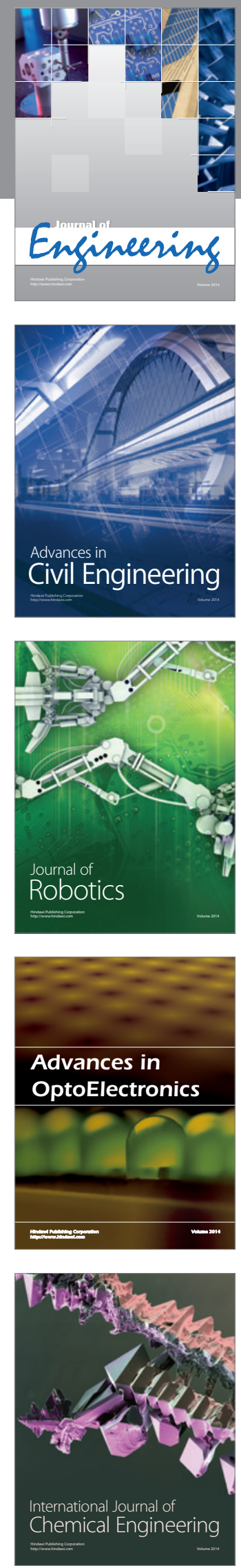

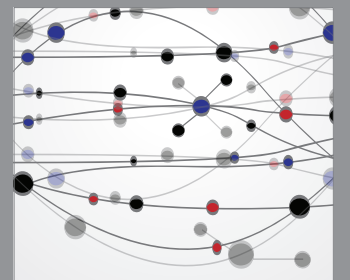

The Scientific World Journal
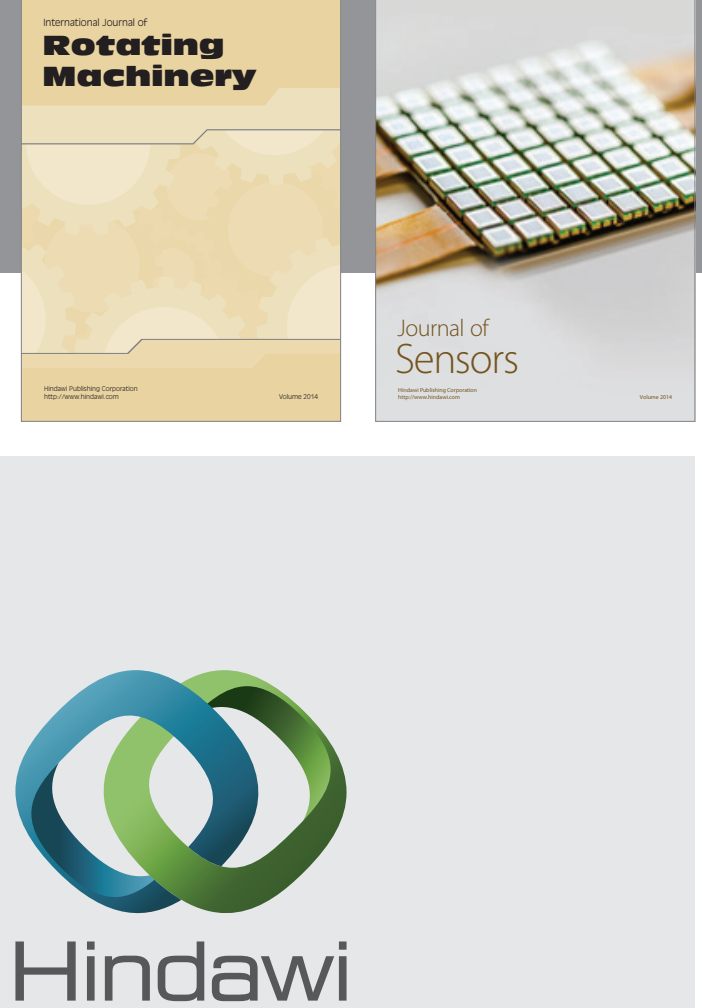

Submit your manuscripts at http://www.hindawi.com
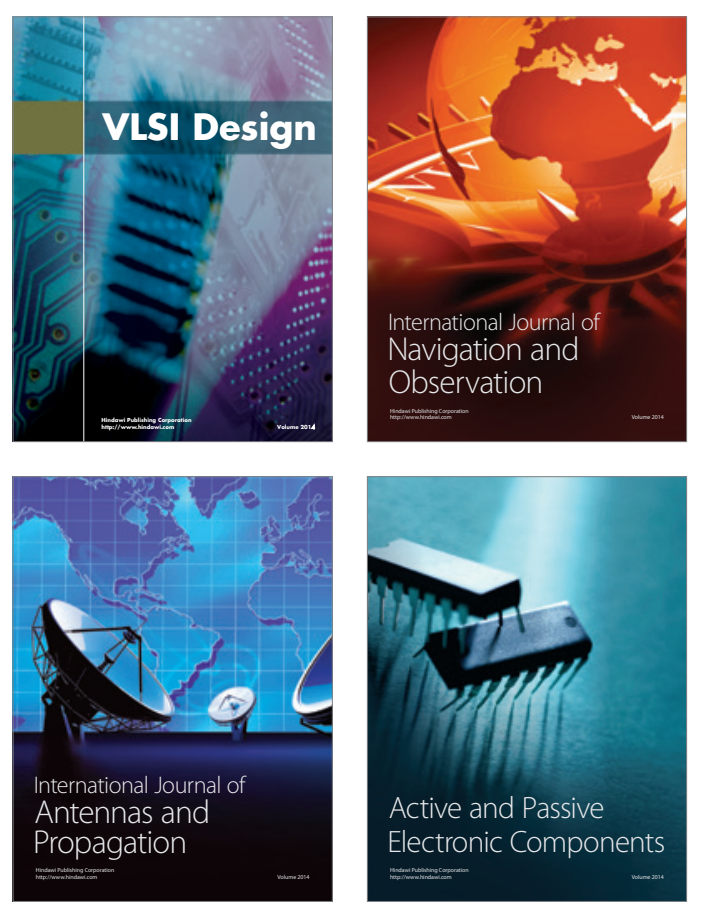
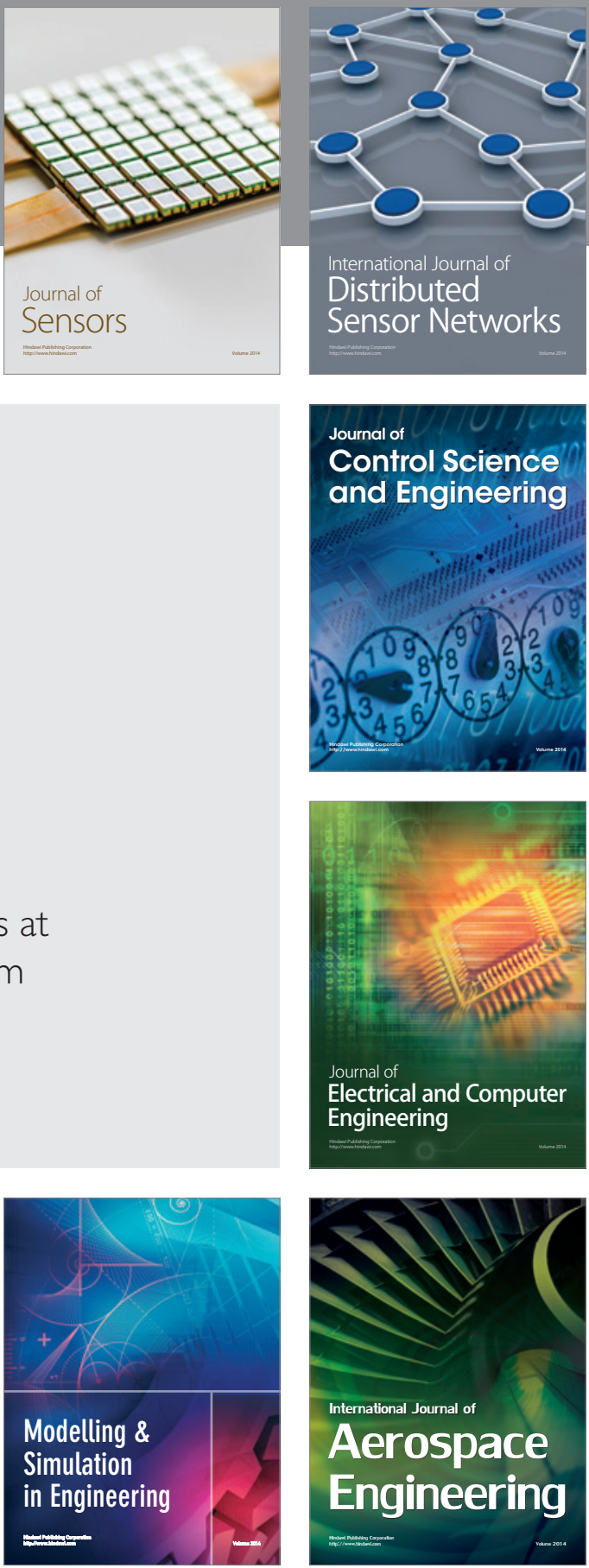

Journal of

Control Science

and Engineering
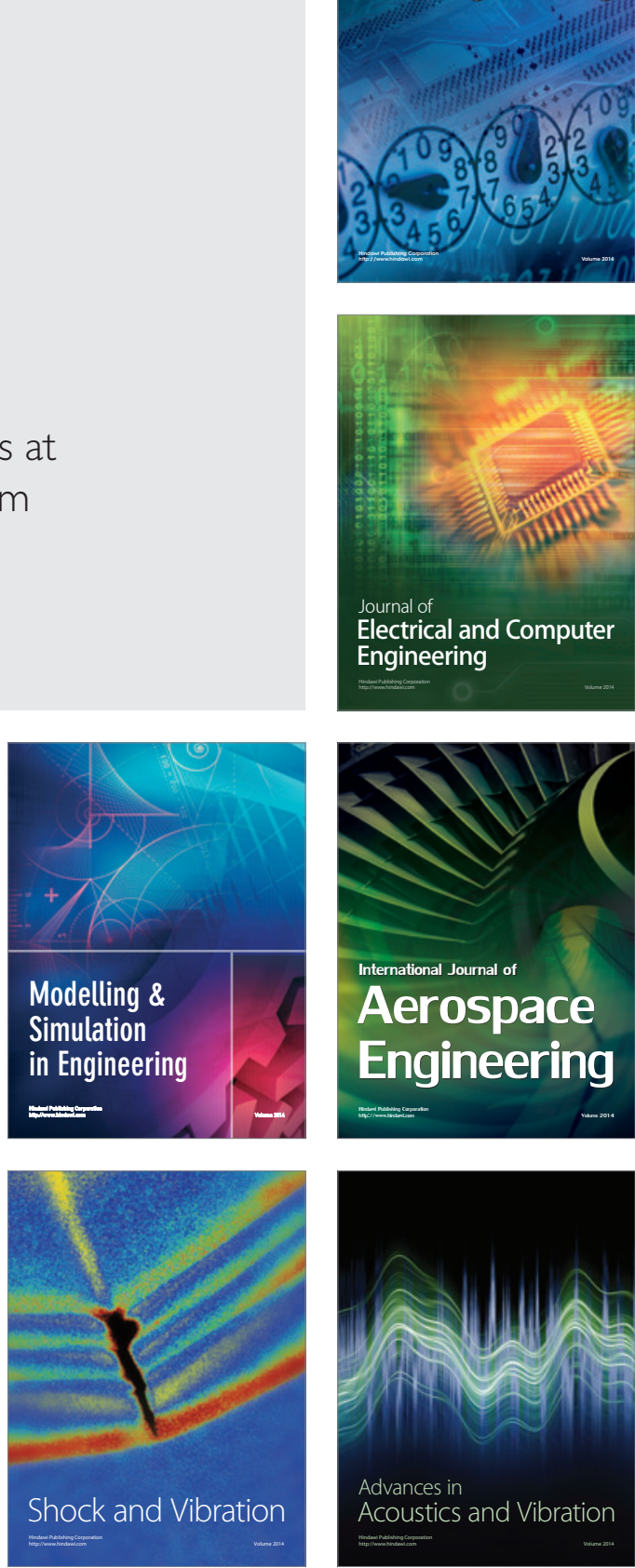